\title{
A commentary on: Affective coding: the emotional dimension of agency
}

\author{
David Smailes ${ }^{1 *}$, Peter Moseley ${ }^{1 \dagger}$ and Sam Wilkinson ${ }^{2}$ \\ ${ }^{1}$ Department of Psychology, Durham University, Durham, UK, ${ }^{2}$ Department of Philosophy, Durham University, Durham, UK
}

Keywords: affect, emotion, agency, hallucinations, voice hearing, psychosis

\section{A commentary on}

Affective coding: the emotional dimension of agency

by Gentsch, A., and Synofzik, M. (2014). Front. Hum. Neurosci. 8:608. doi: 10.3389/fnhum.2014. 00608

\section{OPEN ACCESS}

Edited by:

Lorenzo Pia,

University of Turin, Italy

Reviewed by:

Andreas Kalckert,

Karolinska Institutet, Sweden

*Correspondence:

David Smailes,

david.smailes@durham.ac.uk

${ }^{\dagger}$ Present Address:

Peter Moseley,

School of Psychology, University of Central Lancashire, Preston, UK

Received: 17 January 2015 Paper pending published: 26 January 2015 Accepted: 01 March 2015 Published: 17 March 2015

Citation:

Smailes D, Moseley $P$ and Wilkinson S (2015) A commentary on: Affective coding: the emotional dimension of agency. Front. Hum. Neurosci. 9:142.

doi: 10.3389/fnhum.2015.00142
We welcome Gentsch and Synofzik's (2014) review of the role of affect in modulating a person's sense of agency (SoA). The review is timely and synthesizes a great deal of evidence. However, we feel that their claims concerning the role of affect in modulating a person's SoA could be usefully extended to the study of auditory hallucinations $(\mathrm{AH})$, one unusual experience not discussed in their review. In this commentary, we describe recent findings that suggest that one way in which negative affect plays a role in the development of AH is by reducing the SoA associated with selfgenerated cognitions and suggest that the insula may play an important role in mediating the effect of affect on SoA.

Cognitive models of AH (e.g., Bentall, 1990; Waters et al., 2012) suggest that they occur when a cognition is misattributed to an external, non-self-source. Consistent with this claim, people who experience $\mathrm{AH}$ tend to show a bias toward accepting the presence of a verbal stimulus on tasks designed to measure reality discrimination (i.e., they tend to confuse internal, self-generated events for external, non-self-generated events, but not vice versa; Brookwell et al., 2013). This is often demonstrated using an auditory signal detection task (SDT), in which participants must try to detect speech in an ambiguous auditory stimulus (typically white noise). On trials where the speech is absent, participants have the opportunity to make a false alarm; that is, to report that speech was present in the white noise, when it was not. Presumably, when participants make a false alarm, they have mistaken their internal representation of the speech for the externally presented, "real" speech.

Two recent studies have demonstrated a causal relation between increases in negative affect and weaker reality discrimination. Smailes et al. (2014) reported that participants who performed an auditory SDT after completing a negative mood induction (recalling an unpleasant autobiographical memory) made more false alarms, but not more hits, than did participants who performed the task after completing a neutral mood induction. Similarly, Hoskin et al. (2014), despite employing a different mood induction and a modified SDT, reported that participants were more likely to make false alarms during a condition in which they were exposed to a stressor than during a control condition. Thus, both studies showed that when participants experienced negative affect, they were more likely to misattribute internal, self-generated cognitions to an external source. These findings are consistent with data from studies that have shown that negative affect tends to precede the onset of AH in the daily lives of psychosis patients (Nayani and David, 1996; Delespaul et al., 2002), and suggest that negative affect is associated with the onset of $\mathrm{AH}$, at least in part, because it modulates SoA for cognition. 
Gentsch and Synofzik propose that three stages of agency processing-prospective, immediate, and retrospective-exist. First person accounts (e.g., Romme et al., 2009; Scholtus and Blanke, 2012) suggest that people who experience AH do not go through a deliberative process to determine whether an unusual auditory percept was self-generated, or was a result of an external, non-self agent. Instead, an AH is experienced "in the moment" as something that was not self-generated. Thus, in terms of Gentsch and Synofzik's proposed stages, it seems likely that the effect of negative emotions on a person's reality discrimination abilities would correspond to either prospective or immediate affective coding, rather than retrospective affective coding. That is, negative affect may reduce a person's SoA over cognition by interfering with action planning or with the generation of an accurate sensory outcome representation of a cognition. The most prominent cognitive models of AH suggest that a forward model system acts to predict the sensory outcomes of motor commands, and that dysfunction at one of a number of comparators can lead to a lack of agency over self-generated actions (Jones and Fernyhough, 2007). Interference with either action planning or accurate prediction could therefore lead to external misattributions of self-generated processes. A potential avenue for research would be to investigate whether negative affect can modulate, for example, the sensory attenuation which is associated with successful prediction via forward modeling.

Gentsch and Synofzik's review only briefly discusses the brain regions that may be involved in mediating the effects of

\section{References}

Bentall, R. P. (1990). The illusion of reality: a review and integration of psychological research on hallucinations. Psychol. Bull. 107, 82-95. doi: 10.1037/00332909.107.1.82

Brookwell, M. L., Bentall, R. P., and Varese, F. (2013). Externalizing biases and hallucinations in source-monitoring, self-monitoring and signal detection studies: a meta-analytic review. Psychol. Med. 43, 2465-2475. doi: 10.1017/S0033291712002760

Delespaul, P., de Vries, M., and van Os, J. (2002). Determinants of occurrence and recovery from hallucinations in daily life. Soc. Psychiatry Psychiatr. Epidemiol. 37, 97-104. doi: 10.1007/s001270200000

Farrer, C., Franck, N., Georgieff, N., Frith, C. D., Decety, J., and Jeannerod, M. (2003). Modulating the experiences of agency: a positron emission tomography study. Neuroimage 18, 324-333. doi: 10.1016/S1053-8119(02)00041-1

Farrer, C., and Frith, C. D. (2002). Experiencing oneself vs another person as being the cause of an action: the neural correlates of the experience of agency. Neuroimage 15, 596-603. doi: 10.1006/nimg.2001.1009

Gallagher, S. (2004). Neurocognitive models of schizophrenia: a neurophenomenological critique. Psychopathology 37, 8-19. doi: 10.1159/000077014

Gentsch, A., and Synofzik, M. (2014). Affective coding: the emotional dimension of agency. Front. Hum. Neurosci. 8:608. doi: 10.3389/fnhum.2014.00608

Harrison, B. J., Pujol, J., Ortiz, H., Fornito, A., Pantelis, C., and Yücel, M. (2008). Modulation of brain resting-state networks by sad mood induction. PLOS ONE 3:e1794. doi: 10.1371/journal.pone.0001794

Hoskin, R., Hunter, M. D., and Woodruff, P. W. R. (2014). The effect of psychological stress and expectation on auditory perception: a signal detection analysis. Br. J. Psychol. 105, 524-546. doi: 10.1111/bjop.12048

Jones, S. R., and Fernyhough, C. (2007). Neural correlates of inner speech and auditory verbal hallucinations: a critical review and theoretical integration. Clin. Psychol. Rev. 27, 140-154. doi: 10.1016/j.cpr.2006.10.001 negative affect on SoA. At two points, however, they cite evidence suggesting that damage to/atypical activity in the insula can lead to disorders of SoA. We concur that the insula is a good candidate for mediating the effects of negative affect on SoA. This is because, in addition to the evidence cited by Gentsch and Synofzik, a number of studies have shown (a) that different agency experiences are associated with changes in insula activity (e.g., Farrer and Frith, 2002; Farrer et al., 2003), (b) that insula activity is atypical in people who report AH (Wylie and Tregellas, 2010) and (c) that increases in negative affect are associated with changes in insula activity (Phan et al., 2002; Harrison et al., 2008). Research that examines whether negative affect brings about reductions in a person's SoA over their cognitions through modulation of activity in the insula is required.

Demonstrating that affective problems may play an important role in the development of $\mathrm{AH}$ is important for a number of reasons. First, affect-induced changes in the SoA a person has over their cognitions can help to explain why $\mathrm{AH}$ are typically not experienced constantly (this issue is sometimes raised as a problem for cognitive models of AH; Gallagher, 2004). Seconds, and perhaps more importantly, it opens up the possibility of novel therapeutic interventions. While the primary focus of such interventions may be on ameliorating the affective problems reported by people who hear voices, they may indirectly reduce the frequency of $\mathrm{AH}$ by preventing negative affect-induced modulations of a person's SoA over their cognitions.

Nayani, T. H., and David, A. S. (1996). The auditory hallucination: a phenomenological survey. Psychol. Med. 26, 177-189. doi: 10.1017/S0033291700 $03381 \mathrm{X}$

Phan, K. L., Wager, T., Taylor, S. F., and Liberzon, I. (2002). Functional neuroanatomy of emotion: a meta-anlysis of emotion activation studies in PET and fMRI. Neuroimage 16, 331-348. doi: 10.1006/nimg.2002.1087

Romme, M., Escher, S., Dillon, J., Corstens, D., and Morris, M. (2009). Living with Voices: Fifty Stories of Recovery. Ross-on-Wye: PCCS.

Scholtus, S., and Blanke, C. (2012). "Auditory verbal hallucinations, first-person accounts," in Hallucinations: Theory and Practice, eds J. D. Blom and I. E. C. Sommer (New York, NY: Springer), 105-108.

Smailes, D., Meins, E., and Fernyhough, C. (2014). The impact of negative affect on reality discrimination. J. Behav. Ther. Exp. Psy. 45, 389-395. doi: 10.1016/j.jbtep.2014.04.001

Waters, F., Allen, P., Aleman, A., Fernyhough, C., Woodward, T. S., Badcock, J. C., et al. (2012). Auditory hallucinations in schizophrenia and nonschizophrenia populations: a review and integrated model of cognitive mechanisms. Schizophr. Bull. 38, 683-692. doi: 10.1093/schbul/sbs045

Wylie, K. P., and Tregellas, J. R. (2010). The role of the insula in schizophrenia. Schizophr. Res. 123, 93-104. doi: 10.1016/j.schres.2010.08.027

Conflict of Interest Statement: The authors declare that the research was conducted in the absence of any commercial or financial relationships that could be construed as a potential conflict of interest.

Copyright (C) 2015 Smailes, Moseley and Wilkinson. This is an open-access article distributed under the terms of the Creative Commons Attribution License (CC BY). The use, distribution or reproduction in other forums is permitted, provided the original author(s) or licensor are credited and that the original publication in this journal is cited, in accordance with accepted academic practice. No use, distribution or reproduction is permitted which does not comply with these terms. 